\section{Strontium Ranelate Effect on the Repair of Bone Defects and Molecular Components of the Cortical Bone of Rats}

\author{
Jucely Aparecida da Rosa ${ }^{1}$, Kumiko Koibuchi Sakane ${ }^{2}$, Karina Cecilia Panelli \\ Santos ${ }^{1}$, Vivian Bradaschia Corrêa ${ }^{4}$, Victor Elias Arana-Chavez ${ }^{3}$, Jefferson \\ Xavier de Oliveira ${ }^{1}$
}

\begin{abstract}
This study was conducted to evaluate the effects of treatment with strontium ranelate (SR) on the repair of bone defects and molecular components of bones in femurs. Adult female rats $(n=27)$ were subjected to ovariectomy (OVX) or Sham surgery. Thirty days after surgery, a defect was made in the femur and the animals were then divided into three groups: OVX, SHAM and OVX+SR. Euthanasia was performed four weeks after the bone defect surgery. Repair in bone defect was assessed by computed microtomography $(\mu \mathrm{CT})$ and chemical composition of cortical bone was analyzed by Fourier transform infrared (FIR) spectroscopy and energy dispersive X-ray spectroscopy (EDS). The trabecular thickness (Tb.Th) of the newly formed bone in the OVX+SR group was significantly higher than that for the OVX group. The collagen maturity in the OVX+SR group was smaller than in the other two groups. In this group, a significant increase in the amount of strontium $(\mathrm{Sr})$ and a decrease in the amount of calcium $(\mathrm{Ca})$ embedded to bone tissue were also observed. Systemic treatment with SR improved microarchitecture of the newly formed bone inside the defect, but decreased cross-linking of mature collagen in cortical bone.
\end{abstract}

\author{
'Department of Stomatology, Dental \\ School, USP - Universidade de \\ São Paulo, São Paulo, SP, Brazil \\ ${ }^{2}$ Institute for Research and \\ Development, UNIVAP - Universidade \\ do Vale do Paraíba SP, Brazil \\ ${ }^{3}$ Department of Biomaterials \\ and Oral Biology, Dental School, \\ USP - Universidade de São \\ Paulo, São Paulo, SP, Brazil \\ ${ }^{4}$ Department of Orthopaedic Surgery, \\ New York University School of \\ Medicine, New York, NY, USA
}

Correspondence: Karina Cecília Panelli Santos, Avenida Prof. Lineu Prestes, 2227, Cidade Universitária, 05508-000, São Paulo, SP, Brasil. Tel: +55-11-30917831. e-mail: kapanelli@usp.br

\section{Introduction}

Strontium ranelate (SR) is a drug developed for the treatment of osteoporosis. Its molecule consists of two stable strontium atoms $\left(\mathrm{Sr}^{2+}\right)$, which are the active part of the compound and the ranelic acid organic molecule (1).

Among the drugs used in the treatment of osteoporosis, SR is the only one that demonstrates a dual mode of action on bone metabolism. It favors bone formation (osteogenesis) by stimulating division of osteoblast precursors and increasing synthesis of collagen and noncollagen proteins. Additionally, it simultaneously decreases bone resorption by inhibiting osteoclast differentiation and activity $(2,3)$. Clinical use of SR for the treatment and prevention of osteoporosis has shown positive effects such as increase in bone mineral density and decrease in the risk of bone fracture (4).

The effect of SR on bone repair was investigated in animal models with tibial fracture and showed beneficial results such increases in bone callus and improvement in the biomechanical properties of this tissue $(5,6)$. Use of strontium (Sr) incorporated with a bioactive material has been recently studied for the repair of bone defects in osteopenic animals and the results showed that local release of Sr atoms could improve bone repair (7). Although this drug was proven effective in bone repair, few data regarding their effects on the repair of bone defects are available. Furthermore, little is known about the molecular components of the bone formed during treatment.

Fourier transform infrared (FTIR) spectroscopy has been extensively used in the analysis of molecular components of biomaterials and tissues (8). Studies on bone metabolism and chemical and structural changes caused by bone aging and changes caused by diseases, such as osteoporosis and effects of therapies, were performed in mineralized tissues with FIIR (9-12).

The objectives of this study were to evaluate the effects of ovariectomy and systemic treatment with SR on the organic and inorganic components of cortical bone tissue and to assess whether SR treatment can promote repair of bone defects and improve microarchitecture of the newly formed bone.

\section{Material and Methods Experimental Animals}

Adult rats (Rattus norvegicus, albinus, Wistar, $n=27$; 3 months old; average weight: $250 \mathrm{~g}$ ) were used. The animals were ovariectomized (OVX; $\mathrm{n}=18)$ or subjected to sham surgery (SHAM; $n=9)$. The rats were kept in rooms with controlled temperature $\left(22^{\circ} \mathrm{C}\right)$ rooms, with periodic change (12/12 h) of light, and specifically fed a pelleted diet containing calcium $(\mathrm{Ca} ; 1 \%)$, phosphorus $(\mathrm{P} ; 0.8 \%)$ and vitamin D3 $(5,000 \mathrm{lU} / \mathrm{kg})$. Water and pelleted food were available ad libitum. All experimental procedures 
were approved by the Ethics Committee for Animal Use of the Institute of Biomedical Sciences, University São Paulo (USP), under protocol number 134/2012.

\section{Production of Bone Lesion}

Thirty days after ovariectomy and sham surgery, a bone defect was made in all animals. In all surgical procedures, general anesthesia was obtained by applying an intramuscular injection of $2 \%$ xylazine hydrochloride with $10 \%$ ketamine hydrochloride, in the proportion of $1.0 / 0.5 \mathrm{~mL}$, with a $0.1 \mathrm{~mL} / 100 \mathrm{~g}$ body weight dosage. After dissection of the subcutaneous tissues, a bone defect was made in the left femur (diaphysis region; distal portion). A spherical carbide drill with $2.5 \mathrm{~mm}$ external diameter driven by an electric motor (speed: $1500 \mathrm{rpm}$ ) under constant irrigation ( $0.9 \% \mathrm{NaCl}$ sterile solution) was used. The drill was positioned perpendicular to the long axis of the femur and the cortical bone was cut in a circular shape. After the bone defect was made, the soft tissues were repositioned and sutured.

\section{Pharmacological Treatment}

Treatment started on the next day after the bone lesion. All ovariectomized rats were randomly divided into two groups: OVX $(n=9)$ and $O V X+S R(n=9)$. Animals in the OVX + SR group received SR (Protos ${ }^{\circledR}$, Servier, Gidy, France) orally ( $625 \mathrm{mg} / \mathrm{kg}$ per day; aqueous suspension) by gavage ( $0.3 \mathrm{~mL}$ per animal). The drug was diluted in Milli- $0^{\oplus}$ Water (Millipore, Molsheim, France) and the suspension was administered immediately after it was prepared. A curved stainless-steel needle (length: $38 \mathrm{~mm}$ ) for gavage of rats coupled to a syringe (volume: $1 \mathrm{~mL}$ ) was used to inject the solution directly into the gastrointestinal tract. The animals were weighed weekly on an electronic scale so that the SR solution could be prepared with the correct dosage. The $\mathrm{OVX}$ and SHAM groups received filtered water. All animals were euthanized four weeks after the bone defect surgery. After this procedure, the femur was removed from each animal and excess soft tissue was removed. A scraping with a scalpel blade was made on the cortical surface near the bone defect to obtain samples for spectroscopy. These samples were frozen and then lyophilized for $24 \mathrm{~h}$. The bone specimens were fixed in formaldehyde solution (4\%; phosphate buffer, $0.01 \mathrm{M}$ ). Ovariectomy was evaluated at necropsy by confirming uterine horn atrophy.

\section{Fourier Transform Infrared (FTIR) Spectroscopy}

Potassium bromide $(\mathrm{KBr} ; 150 \mathrm{mg})$ pellets containing lyophilized cortical bone tissue $(1 \mathrm{mg})$ were prepared. Spectra (transmission mode; $4 \mathrm{~cm}^{-1}$ resolution; 12 scans) in the range $4000-400 \mathrm{~cm}^{-1}$ were obtained at controlled temperature $\left(18-20{ }^{\circ} \mathrm{C}\right)$. The Spectrum GX FT-IR (Perkin
Elmer, Boston, MA, USA) spectrometer was used. The spectra were preprocessed with the Spectrum 5.2 (Perkin Elmer) software for baseline correction and normalization. Spectral analyzes were performed using the absorbance mode.

The mineral/matrix proportion was calculated as the ratio between the phosphate $\left(1180-905 \mathrm{~cm}^{-1}\right)$ and amide I+ II amide (1721-1520 $\mathrm{cm}^{-1}$ ) band areas (13). The crystallinity index $(\mathrm{Cl})$ was calculated as the ratio between intensities of the 1057 and $1023 \mathrm{~cm}^{-1}$ sub-bands obtained by curve fitting in the $1200-900 \mathrm{~cm}^{-1}$ region (14). Maturation of collagen was estimated as the ratio between the areas of amide I sub-bands on 1660 and $1690 \mathrm{~cm}^{-1}$ (15).

Curves were adjusted using the Origin Pro 8.0 (Origin ${ }^{\circledR}$, Northampton, MA, USA) software based on information about position provided by deconvolution and second derivative. These adjustments were made using the average spectrum and Gaussian function for calculation of $\mathrm{Cl}$ (six points) and amide I (five points).

\section{Energy-Dispersive $X$-ray Spectroscopy (EDS)}

Presence or absence of Sr atoms incorporated into bone tissue in the OVX + SR group and the amount of calcium (Ca) and phosphorus (P) atoms present in bone tissue samples from all groups were observed by scanning electron microscopy (model EVO-MA40; Zeiss, Jena, Germany) with EDS. For analysis by EDS, lyophilized bone scrapings were placed under a double-sided carbon adhesive tape and observed without any coating.

\section{$X$-ray Computed Microtomography $(\mu \mathrm{CT})$}

Repair of bone defects in femurs was evaluated using the Skyscan (model 1172, Kontich, Belgium) microscanner and the NRecon, DataViewer, CT and CT-Analyzer-Vol software provided by the scanner manufacturer. The images were obtained under the following conditions: voltage: $60 \mathrm{kV}$; tube current: $165 \mu \mathrm{A}$; aluminum filter; thickness: $0.5 \mathrm{~mm}$; rotation: $180^{\circ}$; angular increment: $0.6^{\circ}$ and acquisition of the image with a CCD camera ( $10 \mathrm{Mp}, 8$ radiographic projections per rotation; resolution: $5 \mu \mathrm{m}$ ). The volume of newly formed bone within the defect was defined as volume of interest (VOI), and the volume of the medullary canal and the original bone tissue were excluded from the evaluation. Within VOI after segmentation, the following parameters were measured: bone volume (BV), relative bone volume (BV/TV), and number (Tb.N), thickness (Tb.Th) and separation (Tb.Sp) of trabeculae.

\section{Statistical Analysis}

Data were presented as mean and standard deviation. Statistical analyzes were performed using the R 3.1.0 (R Core Team, 2014; Vienna, Austria) software. Differences between groups were examined using analysis of variance 
(one-way ANOVA). When effects showed to be significant $(p<0.05)$, multiple comparisons were performed by the Tukey's test. Differences were considered significant for all tests with $p<0.05$.

\section{Results}

FTIR

Figure 1 shows the average spectra for each experimental group. Statistical analysis showed that the ratio between areas of the phosphate band and those of amide I and II showed no significant difference between groups ( $p=0.23$ ) (Table 1 ). In the calculation of $\mathrm{Cl}$, the values for ratio between intensities of the 1057 and 1023 $\mathrm{cm}^{-1}$ bands were 1.024, 1.015, and 1.108 for the SHAM, $\mathrm{OVX}+\mathrm{SR}$ and OVX groups, respectively (Fig. 2). Figure 3 shows a spectrum with its underlying bands solved by second derivative and curve-fitting techniques for the amide I band. Two of the underlying bands (1660 and $1690 \mathrm{~cm}^{-1}$ ) are of particular interest because they correspond to the collagen crosslinking pyridinoline (PYR) and dihydroxylysinonorleucine (DHLNL), respectively. The ratio PYR/DHLNL was 3.502, 3.355, and 2.514 in the SHAM, $\mathrm{OVX}$ and $\mathrm{OVX}+\mathrm{SR}$ groups, respectively.

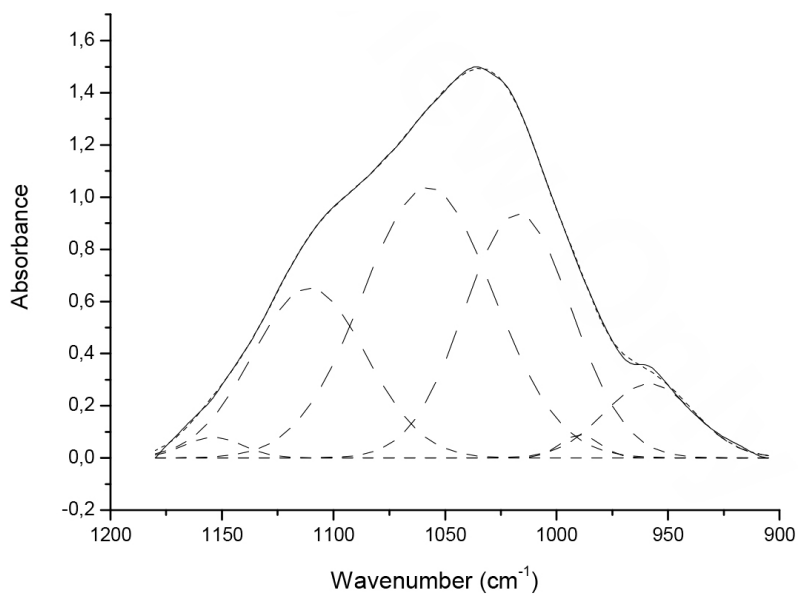

Figure 2. Fitting of curve in the $1200-900 \mathrm{~cm}-1$ region of the IR spectrum. Bone samples were obtained from rats in the OVX group.
EDS

$\mathrm{P}$ and $\mathrm{Ca}$ elements showed to be the main constituents in the samples of the three groups. A significant difference

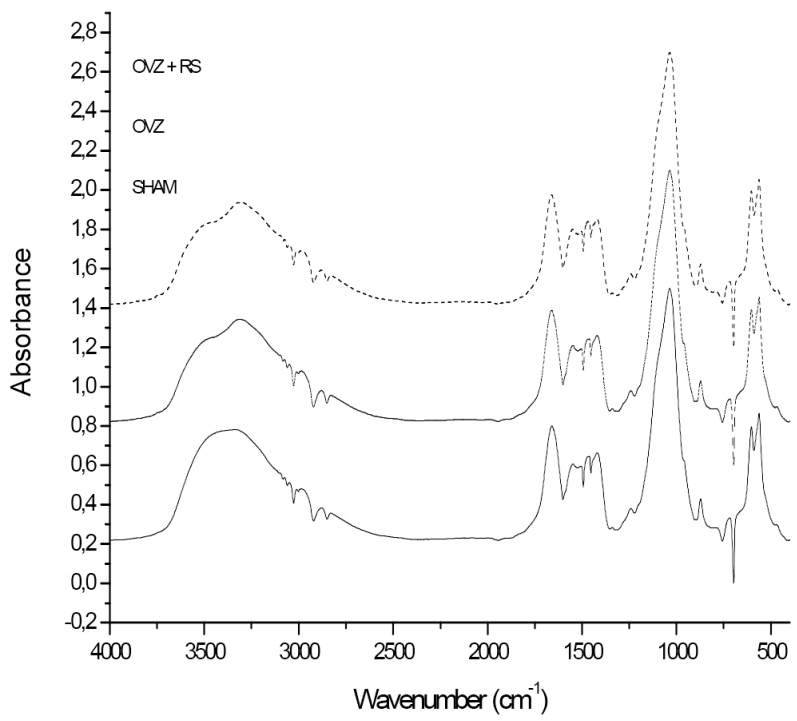

Figure 1. Average FTIR spectra of animals in the SHAM, OVX+SR and OVX groups.

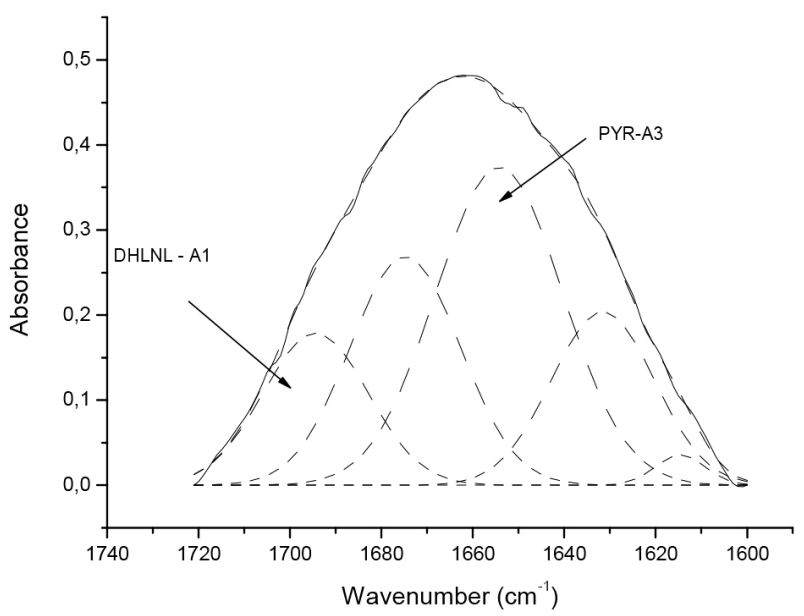

Figure 3. Fitting of in the amide I sub-bands. Bone samples were obtained from rats in the OVX + SR.

Table 1 . Mean values of the variables, by group

\begin{tabular}{|c|c|c|c|c|c|c|c|c|c|}
\hline \multirow{2}{*}{ Variables } & \multicolumn{2}{|c|}{ OVX } & \multicolumn{2}{|c|}{$\mathrm{OVX}+\mathrm{SR}$} & \multicolumn{2}{|c|}{ SHAM } & \multicolumn{2}{|c|}{ Total } & \multirow{2}{*}{$\mathrm{p}$ values } \\
\hline & Mean & SD & Mean & SD & Mean & SD & Mean & SD & \\
\hline Phosphate/Amide I and II & 4.05 & 0.27 & 4.09 & 0.08 & 3.82 & 0.2 & 3.98 & 0.22 & 0.23 \\
\hline $\mathrm{P}$ & 21.2 & 8.92 & 20.2 & 5.82 & 26.88 & 11.21 & 22.76 & 8.81 & 0.512 \\
\hline $\mathrm{Ca}$ & 81.4 & 15 & 47.42 & 11.01 & 81.02 & 17.83 & 69.95 & 21.48 & 0.009 \\
\hline $\mathrm{Sr}$ & 0.18 & 0.34 & 1.36 & 0.79 & 0.17 & 0.33 & 0.57 & 0.76 & 0.009 \\
\hline
\end{tabular}


was observed for the $\mathrm{Ca}$ and $\mathrm{Sr}$ elements in the OVX + SR group $(p=0.009)$, with a decrease in the first and an increase in the second (Table 1).

\section{$\mu C T$}

Figure 4 shows two-dimensional micro-CT images of cross sections in the central region of bone defect in one animal of each group. In Table 2, the quantitative results obtained with micro-CT of bone defects were expressed as BV, BV/TV, Tb.Th, Tb.N and Tb.Sp. In the OVX group, all parameters showed lower values, except Tb.N. As the differences for BV, BV/TV and Tb.Th were significant $(p<0.05)$, Tukey multiple comparisons were performed, and the value for $p$ was set to identify pairs with significant differences.

Significant differences were observed between the SHAM and OVX groups when the BV and BV/TV variables were compared. In the SHAM group, BV were higher than those in the OVX group ( $p=0.014)$ and BV/TV were about $8 \%$ higher than in the OVX group ( $\mathrm{p}=0.015)$. Comparison between the SHAM and OVX + SR groups showed borderline values for these variables. Regarding $\mathrm{Tb}$.Th, a difference was observed between the OVX + SR and OVX groups. In the OVX + SR group, values for Tb.Th were about 1.8\% higher than those in the OVX group $(p=0.049)$. No statistically significant difference was observed between the SHAM and OVX +SR groups.

\section{Discussion}

The results of this study indicate that ovariectomy impaired bone microarchitecture and quality of bone tissue. This conclusion is consistent with results published in other studies in which this model was used $(5,16,17)$. Ovariectomized animals exhibited the lowest averages in almost all morphological parameters (Table 2).

Bone microarchitecture, except Tb.N $(p=0.092)$ and Tb.Sp $(p=0.061$ ), was markedly different among the experimental groups. As Tb.N remained constant, microarchitecture did not differ in terms of topology (Table 2). The OVX + SR group showed intermediate values for the BV and BV/TV variables,
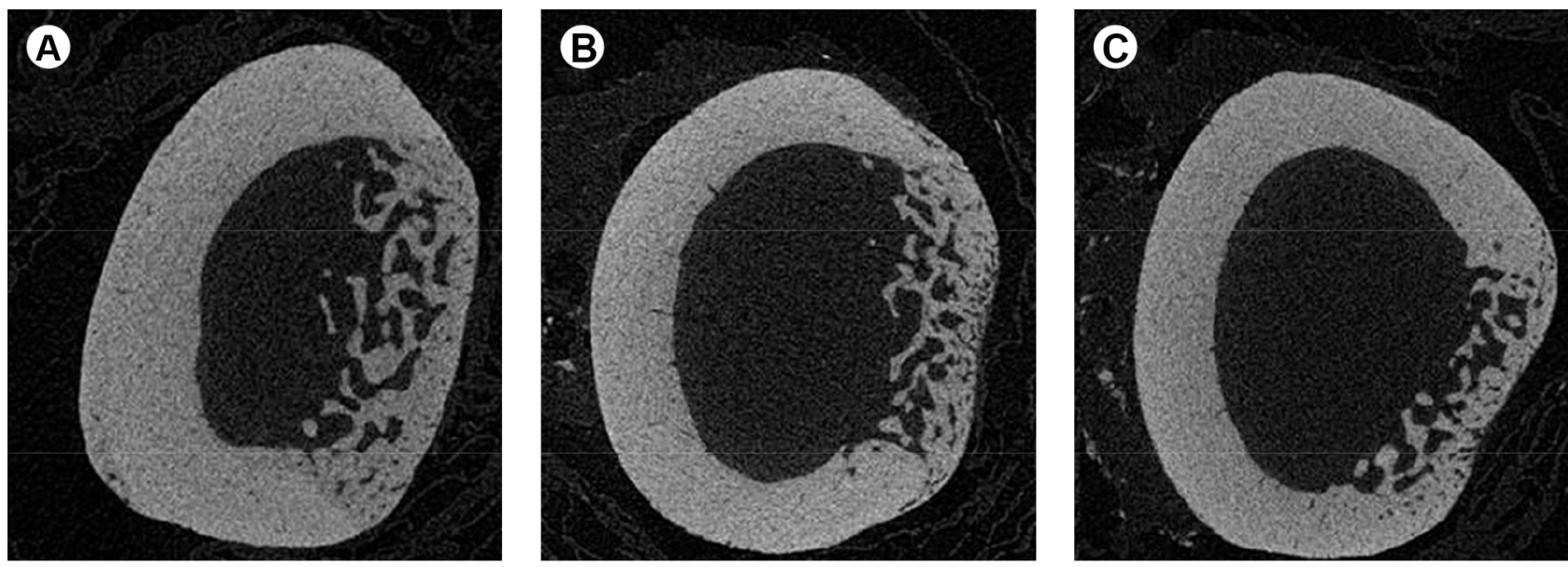

Figure 4. 2D/Two-dimensional images of micro-CT cross-sections in the central region of the bone defect. Bone samples were obtained from rats in the SHAM (A), OVX (B) and OVX+SR (C) groups.

Table 2. Mean values and standard deviations of variables, by group

\begin{tabular}{|c|c|c|c|c|c|c|c|c|c|}
\hline \multirow{2}{*}{ Variables } & \multicolumn{2}{|c|}{ OVX } & \multicolumn{2}{|c|}{$\mathrm{OVX}+\mathrm{SR}$} & \multicolumn{2}{|c|}{ SHAM } & \multicolumn{2}{|c|}{ Total } & \multirow{2}{*}{$\mathrm{p}$ value } \\
\hline & Mean & SD & Mean & SD & Mean & SD & Mean & SD & \\
\hline Bone volume & 1724.7 & 360.41 & 1835.4 & 419.2 & 2293.3 & 393.38 & 1951.1 & 452.3 & 0.012 \\
\hline $\begin{array}{l}\text { Relative bone } \\
\text { volume }\end{array}$ & 25.51 & 5.26 & 26.98 & 6.12 & 33.69 & 5.73 & 28.73 & 6.58 & 0.013 \\
\hline $\begin{array}{l}\text { Thickness of } \\
\text { trabeculae }\end{array}$ & 7.08 & 0.81 & 8.65 & 1.34 & 8.54 & 1.69 & 8.09 & 1.47 & 0.034 \\
\hline $\begin{array}{l}\text { Number of } \\
\text { trabeculae }\end{array}$ & 0.04 & 0.01 & 0.03 & 0.01 & 0.04 & 0.01 & 0.04 & 0.01 & 0.092 \\
\hline $\begin{array}{l}\text { Separation of } \\
\text { trabeculae }\end{array}$ & 24.8 & 4.97 & 31.81 & 5.66 & 31.4 & 8.72 & 29.34 & 7.18 & 0.061 \\
\hline
\end{tabular}


but it had a significant increase in Tb.Th compared with the OVX group. Similar data were observed in another study in which the tibial fracture model was used. Four weeks after fracture, treatment with SR significantly increased the values for BV, TV, Tb.Th, Tb.N and BV/TV compared with the non-treated OVX group (5). Strontium is able to prevent changes in estrogen deficiency-induced bone turnover (18). Thus, inhibition of excessive bone resorption and the promotion of bone formation by SR in the initial period of bone repair may have contributed to these results.

SR therapy was well tolerated and safe and no adverse effect was observed in animals that received medication. This was also reported in a previous publication, in which the authors treated rats with 125, 250, or $625 \mathrm{mg} / \mathrm{kg}$ per day of SR and they did not observe any adverse effect on body weight gain (17).

The animals were fed a diet with normal $\mathrm{Ca}$ concentration (1\%) and this is required for a proper therapeutic interpretation, as Sr serum levels, and thus the $\mathrm{Sr}$ bone levels, are influenced by Ca dietary levels (16). A SR dose equal to $625 \mathrm{mg} / \mathrm{kg}$ per day was used. Such dose in animals fed a normal $\mathrm{Ca}$ diet can lead to a Sr serum concentration similar to that observed in patients treated
In the EDS analysis, Sr incorporation in bone samples was observed in the OVX + SR group. Such incorporation of $\mathrm{Sr}$ was reported to occur mainly in newly formed bone during treatment with SR (19). Regarding Ca concentration in the mineralized matrix, the OVX + SR group showed the lowest mean values among the three groups. This may have occurred because Sr uptake by bone mineral crystals may occur by ion exchange on the surface or substitution of $\mathrm{Ca}$ ions by $\mathrm{Sr}$ ions in the bone $(20,21)$.

The effects of ovariectomy and treatment with SR on cortical bone tissue molecular components were also assessed in this study. Geometry and material properties determine the mechanical strength of bone tissue. Such properties include mineral content, matrix mineral composition, cellular activity, and crystal size and distribution. Most of these material properties, except cellular activity, can be determined by infrared spectroscopy (22).

The study of bone chemistry is hampered by differences between responses of bone trabecular and cortical regions to diseases and medications (23). In the present study with FTIR, were used $\mathrm{KBr}$ pellets made with scrapings from bone tissue cortical surface. The $\mathrm{Cl}$, as measured by the technique of curve fitting in the phosphate band region, increased about $10 \%$ in the OVX group. The OVX + SR group showed a value close to that of the SHAM group, indicating that the treatment maintained bone crystallinity near to that of the control group and this effect is beneficial to the tissue. Studies show that an increase of this index is associated with osteoporotic bone fragility $(9,11)$. Increase in bone crystallinity increases its risk of fracture (13).

The ratio between inorganic and organic components showed no significant difference among groups. Huang et al. (23) used monkeys in their study and observed an increase in the ratio between the phosphate and amide I formed in cortical bone after ovariectomy, whereas trabecular bone did not show any change in phosphate content.

Regarding analysis of collagen maturation, the areas of amide I sub-bands at 1660 and $1690 \mathrm{~cm}^{-1}$ were calculated. The percent ratio of relative areas of these sub-bands is related to enzymatic mature (PYR) and immature (DHLNL) collagen cross-links, which are abundant in mineralized tissues (15). The results showed that treatment with SR caused a decrease in this ratio, as compared with other groups. Abnormalities in enzymatic and non-enzymatic collagen cross-links affect the mineralization process and may lead to microdamage accumulation (24). GourionArsiquaud et al. (13) used FIR to analyze biopsy of the iliac crest in women with and without fracture and found that the value for PYD/DHLNL was significantly higher in patients with fracture. Farlay et al. (25) used mice with a characterized decrease in collagen cross-linking after inhibition of lysyl oxidase. They used FIR to determine the ratio 1660 and $1690 \mathrm{~cm}^{-1}$ in bone tissue and compared it with collagen cross-links as determined by liquid chromatography. They concluded that this ratio is unrelated to collagen cross-linking but it increases with bone mineral age, suggesting that a modification of this ratio could be mainly due to a modification of the collagen secondary structure related to the mineralization process. However, the authors did not use second derivative spectroscopy or deconvolution methods to determine the number and position of the underlying peaks of the amide I band.

In conclusion, the present study demonstrated that systemic treatment with SR promoted bone repair and improved microarchitecture of the newly formed bone within the defect. However, the results of the cortical surface analyzes near the bone defect with FIIR data suggest that SR decreased cross-linking of mature collagen.

\section{Resumo}

Este estudo foi conduzido para avaliar os efeitos do tratamento com ranelato de estrôncio (RE) na reparação de defeitos ósseos e componentes moleculares de ossos nos fêmures. Ratas adultas $(n=27)$ foram submetidas a ovariectomia (OVX) ou cirurgia Sham. Trinta dias após a cirurgia, um defeito foi feito no fêmur e os animais foram então divididos em três 
grupos: OVX, SHAM e OVX+RE. A eutanásia foi realizada quatro semanas após a cirurgia de preparo do defeito ósseo. A reparação do defeito ósseo foi avaliada por microtomografia computorizada $(\mu \mathrm{CT})$ e a composição quimica do osso cortical foi analisada por espectroscopia de infravermelho de transformada de Fourier (FIIR) e espectroscopia por energia dispersiva de raios $X$ (EDS). A espessura do osso trabecular (Tb.Th) recém formado no grupo $\mathrm{OVX}+\mathrm{SR}$ foi significativamente maior que a do grupo OVX. A maturidade do colágeno no grupo $\mathrm{OVX}+\mathrm{SR}$ foi menor do que nos outros dois grupos. Neste grupo, observou-se também um aumento significativo na quantidade de estrôncio $(\mathrm{Sr})$ e uma diminuição na quantidade de cálcio (Ca) no tecido ósseo. 0 tratamento sistêmico com RE melhorou a microarquitetura do osso recém formado dentro do defeito, mas diminuiu a reticulação do colágeno maduro no osso cortical.

\section{References}

1. Marie PJ, Felsenberg D, Brandi ML. How strontium ranelate, via opposite effects on bone resorption and formation, prevents osteoporosis. Osteoporos Int 2011;22:1659-1667.

2. Marie PJ. Strontium ranelate: a novel mode of action optimizing bone formation and resorption. Osteoporos Int 2005; 16:S7-S10.

3. Przedlacki J. Strontium ranelate in post-menopausal osteoporosis. Endokrynol Pol 2011;62:65-72.

4. Reginster JY, Kaufman JM, Goemaere S, Devogelaer JP, Benhamou CL, Felsenberg D, et al.. Maintenance of antifracture efficacy over 10 years with strontium ranelate in postmenopausal osteoporosis. Osteoporos Int 2012;23:1115-1122.

5. Li YF, Luo E, Feng G, Zhu SS, Li JH, Hu J. Systemic treatment with strontium ranelate promotes tibial fracture healing in ovariectomized rats. Osteoporos Int 2010;21:1889-1897.

6. Ozturan KE, Demir B, Yucel I, Cakıcı H, Yilmaz F, Haberal A. Effect of strontium ranelate on fracture healing in the osteoporotic rats. J Orthop Res 2011;29:138-142.

7. Wei L, Ke J, Prasadam I, Miron RJ, Lin S, Xiao Y, et al.. A comparative study of Sr-incorporated mesoporous bioactive glass scaffolds for regeneration of osteopenic bone defects. Osteoporos Int 2014;25:2089-2096.

8. Camacho NP, Carroll P, Raggio CL. Fourier transform infrared imaging spectroscopy (FT-IRIS) of mineralization in bisphosphonate-treated oim/oim mice. Calcif Tissue Int 2003;72:604-609.

9. Boskey A, Mendelsohn R. Infrared analysis of bone in health and disease. J Biomed Opt 2005;10:031102.

10. Kimura-Suda H, Kajiwara M, Sakamoto N, Kobayashi S, Ijiro K, Yurimoto $\mathrm{H}$, et al.. Studies on bone metabolism by using isotope microscopy, FIR imaging, and micro-Raman spectroscopy. J Oral Biosci 2013;55:61-65.

11. Paschalis EP, Betts F, DiCarlo E, Mendelsohn R, Boskey A. FTIR microspectroscopic analysis of human iliac crest biopsies from untreated osteoporotic bone. Calcif Tissue Int 1997;61:487-492.

12. Paschalis EP, Mendelsohn R, Boskey AL. Infrared assessment of bone quality: a review. Clin Orthop Relat Res 2011;469:2170-2178.

13. Gourion-Arsiquaud S, Faibish D, Myers E, Spevak L, Compston J, Hodsman $A$, et al.. Use of FTIR spectroscopic imaging to identify parameters associated with fragility fracture. J Bone Miner Res 2009;24:1565-1571.

14. Pleshko N, Boskey A, Mendelsohn R. Novel infrared spectroscopic method for the determination of crystallinity of hydroxyapatite minerals. Biophys J 1991;60:786-793.

15. Paschalis EP, Verdelis K, Doty SB, Boskey AL, Mendelsohn R, Yamauchi M. Spectroscopic characterization of collagen cross-links in bone. J Bone Miner Res 2001;16:1821-1828.

16. Fuchs RK, Allen MR, Condon KW, Reinwald S, Miller LM, McClenathan $D$, et al.. Strontium ranelate does not stimulate bone formation in ovariectomized rats. Osteoporos Int 2008;19:1331-1341.

17. Bain SD, Jerome C, Shen V, Dupin-Roger I, Ammann P. Strontium ranelate improves bone strength in ovariectomized rat by positively influencing bone resistance determinants. Osteoporos Int 2009;20:1417-1428.

18. Morohashi T, Sano T, Harai K, Yamada S. Effects of strontium on calcium metabolism in rats. II. Strontium prevents the increased rate of bone turnover in ovariectomized rats. Jpn J Pharmacol 1995;68:153-159.

19. Boivin G, Farlay D, Khebbab MT, Jaurand X, Delmas PD, Meunier PJ. In osteoporotic women treated with strontium ranelate, strontium is located in bone formed during treatment with a maintained degree of mineralization. Osteoporos Int 2010;21:667-677.

20. Boivin G, Meunier PJ. The mineralization of bone tissue: a forgotten dimension in osteoporosis research. Osteoporos Int 2003;14: S19-S24.

21. Farlay D, Boivin G, Panczer G, Lalande A, Meunier PJ. Long-term strontium ranelate administration in monkeys preserves characteristics of bone mineral crystals and degree of mineralization of bone. J Bone Miner Res 2005;20:1569-1578.

22. Boskey AL, Goldberg M, Kulkarni A, Gomez S. Review: Infrared imaging microscopy of bone: Illustrations from a mouse model of Fabry disease. Biochim Biophys Acta 2006;1758:942-947.

23. Huang RY, Miller LM, Carlson CS, Chance MR. In situ chemistry of osteoporosis revealed by synchrotron infrared microspectroscopy. Bone 2003;33:514-521.

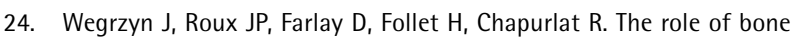
intrinsic properties measured by infrared spectroscopy in whole lumbar vertebra mechanics: organic rather than inorganic bone matrix? Bone 2013;56:229-233.

25. Farlay D, Duclos M-E, Gineyts E, Bertholon C, Viguet-Carrin S, Nallala J. The ratio $1660 / 1690 \mathrm{~cm}^{-1}$ measured by infrared microspectroscopy is not specific of enzymatic collagen cross-links in bone tissue. PLoS ONE. 2011;6: e28736. 